\title{
Memória e história em Xosé Lois García: a poética dos vencidos
}

\author{
Memory and history in Xosé Lois García: the poetic of the losers
}

\author{
Sirlei da Silva FONTOURA* \\ Universidade Estadual do Centro-Oeste (UNICENTRO) \\ Cláudio José de Almeida MELLO** \\ Universidade Estadual do Centro-Oeste (UNICENTRO)
}

\begin{abstract}
RESUMO: A partir dos contextos histórico, político e social em que se inscreve Xosé Lois García, poeta que representa um importante papel na cultura e literatura galegas, o presente trabalho tem como objetivo explicitar de que forma história e memória estão entrelaçadas na sua produção poética para configurar o que identificamos como uma poética dos vencidos. Para tanto, utilizamos pesquisas acerca da memória para compreender em que medida a memória coletiva povo galego é representada pela situação sombria retratada na poesia de Xosé Lois Garcia, com versos que podem ser considerados signos de resistência contra o esquecimento da violência imposta à comunidade galega durante a Guerra Civil Espanhola, e registrada pela historiografia oficial. Trata-se de um trabalho de análise e crítica literária de natureza qualitativa, embasado em material bibliográfico embasado de autores como Halbwachs (2004), Benjamin (1986), Jelin (1998), Torres (2015).
\end{abstract}

PALAVRAS-CHAVE: Literatura galega. História. Memória coletiva.

ABSTRACT: From the historical, political and social contexts in which it is part Xosé Lois García, poet who plays an important role in the Galician culture and literature, this paper aims to explain how history and memory are intertwined in his poetry to set what we identify as a poetic of losers. Therefore, we use research on memory to understand to what extent the collective memory of the Galician people is represented by the grim situation portrayed in the poetry of Xosé Lois García, with verses that can be considered resistance signs against forgetting the violence imposed on the Galician community during the Spanish Civil War, and recorded by official historiography. It is a work of analysis and literary criticism of a qualitative nature, based on grounded bibliography of authors such as Halbwachs (2004), Benjamin (1986), Jelin (1998), Torres (2015).

KEYWORDS: Galician literature. History. Collective memory.

Recebido em 3 de outubro de 2016. Aprovado em 18 de novembro de 2016.

\footnotetext{
*Mestranda em Letras. Universidade do Centro-Oeste do Paraná. Professora do Departamento de Pedagogia - Faculdade Guairacá. sirleifontoura@gmail.com

${ }^{* *}$ Doutor em Letras. Professor Associado da Universidade Estadual do Centro-Oeste. claudiomello10@gmail.com
} 


\section{Introdução}

Xosé Lois García nasceu em Lugo (Galiza) em 1945. É um autor que se dedica a vários gêneros literários, como poesia, narrativa, ensaios, teatro, artigos jornalísticos, crítica literária e literatura infantil. Mesmo com grande representatividade nos cenários literário e cultural galegos, ainda é pouco conhecido em solo brasileiro, motivo pelo qual se justifica o interesse pelo seu trabalho, de reconhecida qualidade estética.

Ele nasceu e viveu boa parte da sua vida no meio rural galego oprimido, explorado e desprezado pela burguesia espanhola, bem como agredido pelos falangistas e franquistas. Nesse contexto, sua infância foi difícil, marcada pelas dificuldades econômicas da sua família e, sobretudo, pela opressão social e política impostas na época aos que se opunham ao regime franquista. Em meados da década de 60, ele decidiu emigrar a Barcelona, considerada um lugar promissor, a fim de melhorar de vida no plano econômico, bem como no plano intelectual e acadêmico. Mesmo longe, García não se esqueceu de sua terra natal, fortemente marcada pela Guerra Civil Espanhola, transformando a saudade e as lembranças individuais em poesia.

O objetivo do presente trabalho é explicitar de que forma história e memória estão entrelaçadas na sua produção poética. Dentre tantas possiblidades de pesquisas acerca da memória, interessa compreender os estudos relacionados à memória coletiva, a fim de estudar a memória do povo galego representada pela situação sombria retratada nos versos de Xosé Lois Garcia, versos que podem ser considerados signos de resistência contra o esquecimento da violência imposta à comunidade galega durante a Guerra Civil Espanhola e a ditadura franquista.

O presente trabalho, portanto, desdobra-se em três partes. Num primeiro momento, os conceitos de história e memória e as confluências entre esses dois domínios. Em seguida, tratar-se-á das memórias individual e coletiva para mostrar de que forma estão manifestas na poética de García. Por fim, a partir da rememoração de fatos passados, a explicitação do compromisso do autor com a história da Galiza, ao escrever versos que podem ser considerados signos de resistência contra o apagamento da história dos vencidos. 


\section{História e memória: confluências?}

As relações entre história e memória sempre foram inquietantes, apesar daquilo que as aproxima, o tempo passado. Nessa perspectiva, abordaremos as questões que as problematizam e as que as aproximam, visto que nos últimos tempos, várias transformações marcaram o debate sobre os registros historiográficos e os memorialísticos.

De forma enfática, Nora estabeleceu a diferença entre memória e história que, "longe de serem sinônimos, tomamos consciência que tudo opõe uma à outra" (1993, p. 9). Segundo Nora, a memória é vida, está em evolução permanente, sempre carregada por grupamentos vivos e, consequentemente, aberta à dinâmica da lembrança e do esquecimento. Além disso, é um fenômeno sempre atual, alimenta-se de lembranças vagas, globais ou flutuantes, particulares ou simbólicas. Por emergir de um grupo social, ela é múltipla e desacelerada, coletiva, ao mesmo tempo individualizada e plural. Já a história é a reconstrução problemática e incompleta daquilo que não mais existe, ou seja, é uma representação do passado por meio de um discurso crítico que demanda análise. A história pertence a todos e a ninguém, questão que lhe dá uma vocação universal (NORA, 1993, p. 9).

Lowenthal (1998) também aponta diferenças, afirmando que ao contrário da memória, a história é baseada em fontes empíricas, as quais podemos aceitar ou rejeitar por outras versões do passado. No entanto, caso haja confiança na própria memória, não se pode reivindicar quaisquer tipos de conhecimentos do passado. Já se não existem provas concretas, os dados históricos podem, sim, ser contestados (LOWENTHAL, 1998, p. 107).

Alguns dos principais traços que distinguem a memória da história, são a continuidade, característica de toda a memória, e a descontinuidade, envolvida na operação historiográfica (HALBWACHS, 2004). Ou seja: com relação à História, como sucessão de estruturas, a memória coletiva é de extrema relevância, visto que cumpre a função de religar tradições e reestabelecer continuidades que a historiografia não oferece. Para exemplificar, Halbwachs faz referência aos acontecimentos que abalam fortemente os alicerces de uma época e permite o surgimento de novos paradigmas. Assim, a memória coletiva entra em cena para criar uma continuidade ilusória, 
continuidade aos homens de períodos críticos em que uma estrutura pode passar a outra (BARROS, 2011, p. 325).

A memória coletiva também é feita de descontinuidades, entretanto disfarçadas de continuidade. Dessa forma, é possível assegurar a sensação humana e social de unidade, permitindo aos homens que atravessem os períodos históricos mais turbulentos. Desse modo, compreende-se que a memória coletiva se forma a partir dos grupos sociais que são os seus portadores. Logo, quando ela "esquece uma quantidade tão grande de fatos e personalidades antigas, é porque os grupos que guardavam sua lembrança desapareceram” (HALBWACHS apud BARROS, 2011, p. 326). Quando esses grupos desaparecem, a solução para que se salvem as lembranças "é fixá-las por escrito em uma narrativa, uma vez que as palavras e os pensamentos morrem, mas os escritos permanecem" (HALBWACHS, 2004, p. 80).

Nessa perspectiva, essa aproximação entre memória e história valoriza, por exemplo, os testemunhos orais, os quais passaram a ser registrados, reconhecendo-se a subjetividade de quem o evocava, vendo-os como uma fonte a mais de pesquisa histórica. É o caso do Projeto Investigação Interuniversitario Nomes e Voces, criado em 2006 pelas universidades de Santiago de Compostela, A Coruña e Vigo, na Galiza. O objetivo principal desta ação é constituir um espaço de investigação e documentação para o estudo histórico da repressão que sofreu a Galiza durante a Guerra Civil Espanhola e os anos de ditadura franquista. Sente-se a necessidade de conhecer um passado que precisa ser esclarecido a partir de memórias que se restrinjam ao âmbito individual ou familiar que, por inúmeras razões, permanecem ainda ocultas. Para a recuperação dos dados memorialísticos, uma relação de nomes das vítimas da repressão é elaborada, além do estudo de fontes escritas, fontes orais e estudos locais, bem como entrevistas feitas aos protagonistas sobreviventes daqueles períodos.

Outro exemplo de esclarecimento de um passado oculto é aquele realizado por meio da produção cultural, mais especificamente a literatura. Se existem a história e as memórias oficiais, existem a história e as memórias colocadas em segundo plano, forjadas por um discurso hegemônico. Nesse sentido, o escritor, como que exercendo a figura de um historiador, é quem vai narrar literariamente os acontecimentos, as experiências dos fatos sociais e históricos, por meio de suas obras. 
Em suma, em certa medida, há consenso entre os estudiosos de que memória e história não se confundem. Contudo, como vimos, a memória pode se atrelar à história e a ela ser de grande importância para a produção de narrativas, mesmo que estas se apresentem na forma de uma Nova História, a dos vencidos (BENJAMIN, 1986), valorizando-se as experiências próprias dos indivíduos, as situações singulares que sucumbiram no passado, como veremos adiante.

\section{Das lembranças}

$\mathrm{Na}$ sua significação mais usual, a memória corresponde ao processo limitado de trazer à tona as recordações. Esse processo não é preciso, pois envolve o esquecimento, reconstruções, omissões, parcialidades. A concepção que da memória se tinha estava relacionada a um depósito de dados.

Entretanto, mudanças conceituas emergiram, mostrando-nos que a memória do indivíduo se apresenta de forma ativa, dinâmica, criativa e interativa, pois envolve aspectos como o "comportamento narrativo", considerado como fundamental por Janet em seu ensaio de 1972, A memória (BARROS, 2011).

Se a memória individual envolve "comportamento narrativo", deve-se considerar antes de mais nada que a narratividade é produto da linguagem, e esta produto da sociedade. Consequentemente, a dimensão coletiva interfere na memória individual, ou seja, memória individual e memória coletiva acabam por, digamos, estreitar relações.

Por meio das lembranças, os indivíduos nunca estão só, mas sim em interação com o meio social, um meio onde as lembranças são construídas. Nesse sentido, o social influi na construção da memória, ou seja, reflexões e sentimentos são inspirados pela sociedade, o que reafirma o papel da memória individual, visto que "está enlaçada à memória do grupo, que por sua vez está integrada à memória mais ampla da sociedade a memória coletiva" (MALUF, 1995, p. 35).

Em García, as experiências individuais estão relacionadas à ditadura franquista, o que se compreende quando se leva em conta que o autor nasceu durante este período. Porém, as lembranças dos anos de guerra, anteriores ao seu nascimento, também emergem, contadas pelos outros ou por leituras. Em outras palavras, trata-se da memória como uma representação do passado, construída a partir do conhecimento 
cultural compartilhado pelas gerações passadas e por diversos "outros" que também não viveram diretamente as experiências. Portanto, é possível elaborar memórias a partir das narrativas dos outros que as fizeram, transmitiram e dialogaram (JELIN, 1998), como vemos nos excertos abaixo:

\section{[...]}

Meu pai contábame contos e despois falábame de todo o que ía tecendo nocturno neboeiro. ${ }^{1}$ (GARCÍA, 2005, p. 208)

\section{[...]}

Meu pai non tiña viño só anacos de odre e aí gardaba barbarie e desenganos.<smiles>[AlH2]</smiles>

Discretas choivas na memoria xerminan meu pai coñecía orxías e crimes fascistas ${ }^{2}$

(GARCÍA, 2005, p. 304)

Os versos aludem a fatos históricos, porém apagados pelo "silenciamento dos vencidos", na perspectiva de Benjamin (1986). Sabendo da morte do cirurgião Dr. Rafael de Vega Barrera pelos militares sublevados contra a República, o pai de Xosé Lois não deixou de elogiar a sua figura e personalidade, devido à ajuda que dele havia recebido no passado para a realização de uma cirurgia de urgência. Por este motivo, foi detido e torturado pelos fascistas durante a Civil Espanhola, um cenário de conflitos entre comunistas e fascistas, iniciado em julho de 1936, sob o comando de Francisco Franco, o qual travou lutas sangrentas que resultaram em um país imerso numa situação de caos e horror. Na Galiza, como de resto em outras partes da Espanha, a violência foi extrema. Durante os três anos de guerra, estima-se que, dentro do caráter eminentemente seletivo da repressão como resultado de morte, o total de vítimas tenha sido de 4.590 pessoas (CAYADO, ALMANSA, PRIETO, 2010). As mortes não ocorreram somente pelas atitudes contrárias ao golpe, mas também por as vítimas serem pessoas com reconhecimento público, ligadas ao ativismo na sociedade liberal e

\footnotetext{
1 Tradução nossa: "Meu contava-me contos e depois falava-me / de todo o que ia tecendo noturno nevoeiro".

2 Tradução nossa: "Meu pai não tinha vinhos só pedaços de odre / e aí guardava barbáries e desenganos. [...] Discretas chuvas na memória germinam / meu pai conhecia orgias e crimes fascistas".
} 
progressista, com formação cultural, os quais lutavam pela cessão de direitos e espaços na esfera social à classe média e aos trabalhadores. Toda esta situação continuou de forma massiva durante a ditadura franquista nas vilas, bem como no meio rural galego, lugar onde as mazelas sociais e a opressão sofridas eram palpáveis.

Nesse contexto, ao trazer à tona as lembranças do menino filho de camponeses, o poeta, comprometido com a palavra, denuncia as situações degradantes impostas pelo governo da época aos galegos.

\section{Un domingo vintedous de abril eu nacía destinado á pobreza dunha casa que tiña un candil con luz irreal e de xentileza.}

Aquela lenta sombra de agonia que nos lenzos íame cobrindo tiña ese eco e mensaxe de ira, atadura que vai desunindo. ${ }^{3}$ $[\ldots]$

(GARCÍA, 2007, p. 78)

No poema acima, o eu lírico se refere ao dia do seu nascimento, dia em que nasceu "destinado á pobreza", em meio à difícil situação econômica que enfrentava sua família. Junto aos "lenzos" uma "lenta sombra de agonia" o cobria, carregada de um “eco e mensaxe de ira". Ira advinda do Império espanhol, ira que não afetava somente a sua família, mas sim todas as que viviam no meio rural galego, as quais lutavam diariamente pela sobrevivência, pois há tempo sofriam pela má distribuição de terras. Enquanto na Galiza estava presente uma estrutura minifundiária, com lotes pequenos que sustentavam apenas uma família, nas regiões do rio Tejo os latifúndios predominavam (BUADES, 2013). Dessa forma, as famílias viviam imersas em "vivencias arrepiantes de pobres / que nunca tiñan fin"4 (GARCÍA, 1988, p. 54). A partir disso, identificamos em Xosé Lois um poeta que traz consigo a dor e a violência que historicamente viveu o povo galego (MOURA, 2009, p. 82).

\footnotetext{
3 Tradução nossa: "Um domingo vinte e dois de abril / eu nascia destinado à pobreza / de uma casa que tinha um candeeiro / com luz irreal e de gentileza. / Aquela lenta sombra de agonia / que nos lenços ia-me cobrindo / tinha esse eco e mensagem de ira / atadura que vai desunindo".

${ }^{4}$ Tradução nossa: "vivencias arrepiantes de pobres / que nunca tinham fim”.
} 
Como podemos observar, experiências individuais estão materializadas em seus poemas, entretanto, como já vimos, mesmo que se faça referência a uma memória individual, esta passa a ser coletiva, visto que, ao expressar seus próprios sentimentos, o poeta também expressa os da coletividade.

\section{Um compromisso com a história}

Da memória individual à memória coletiva, revela-se a representação de um período histórico que marcou o povo galego. Nesse sentido, por meio do eu-lírico, García assume um compromisso com a história da Galiza, visto que em suas poesias se reflete a sociedade da época. Assim, história e poesia estão relacionadas a partir de uma ideologia comprometida com um ponto de vista social de baixo.

Nessa perspectiva, Paz afirma que o ato poético se concretiza por meio da história, sendo considerado uma expressão social que não se separa das manifestações históricas, isto é, “o poema não teria sentido - nem sequer existência - sem a história, sem a comunidade que o alimenta e à qual alimenta" (1982, p. 226). Para o autor, o poema é histórico de duas formas: como produto social e como criação que transcende o histórico, mas que para ser verdadeiramente precisa se encarnar novamente na história e se repetir entre os homens (PAZ, 1982, p. 228).

Entretanto, o sentido do poema não é esgotado, já que se trata de dois domínios com características distintas: a história exige a veracidade para que se diga que o discurso é historiográfico (BOSI, 1983, p. 138); o discurso poético, por sua vez

[...] jamais é completamente deste mundo, sempre nos leva mais além, a outras terras, a outros céus, a outras verdades. A poesia parece escapar à lei da gravidade da história, porque sua palavra nunca é inteiramente histórica. A imagem nunca quer dizer isto ou aquilo. Sucede justamente o contrário, como já se viu: a imagem diz isto ou aquilo. E mais ainda: isto é aquilo". (PAZ, 1982, p. 226).

O discurso poético ultrapassa "o círculo dos significados relativos" e "dizem o indizível" (PAZ, 1982, p. 231). Portanto, o poema não explica a realidade, nem sequer a recria, mas sim a representa literariamente a partir de circunstâncias históricas vivenciadas pelo poeta. Tais experiências tornam-se palavras e, consequentemente, ocorre a materialização de uma experiência histórica, fator que torna a poesia "um produto histórico, filho de um tempo e de um lugar" (PAZ, 1982, p. 231). 
Outro ponto a ser ressaltado é a insistência de um passado que não quer ser ocultado. Para isso, a memória insiste na sua presença, mesmo havendo forças contrárias para isso, como por exemplo, as políticas de memória instituídas na Espanha durante o Franquismo. Segundo Michel (2010, p. 15), essas políticas estão relacionadas a um conjunto de intervenções do governo, objetivando a produção e imposição de lembranças comuns a toda uma sociedade, monopolizando instrumentos de ações públicas, como as comemorações oficiais, programas escolares de história, leis memoriais, etc. Em outras palavras, uma narrativa seria monopolizada para a união de membros ao redor de uma história comum, ignorando a memória coletiva de um povo.

Nesse sentido, durante o período ditatorial as ações diretas foram a censura, o monopólio de produção de informação, educação cívica através de datas comemorativas, escola como principal meio de reprodução do discurso oficial e do projeto da Espanha através do ensino de História, etc. Ações como estas tornaram a Memória Oficial difícil de ser disseminada, promovendo ao mesmo tempo uma "política de esquecimento", por meio do esquecimento-destruição. Ou seja, governos totalitários se esforçam para controlar o conjunto de expressões públicas da memória, nesse caso a dos "vencidos", buscando a imposição de uma única verdade oficial da História, reprimindo a memória coletiva, nesse caso as memórias consideradas rivais (MICHEL, 2010, p. 23).

Assim, escolhe-se o que se quer dizer ou não, elevando-se os heróis da nação e apagando a presença de outros. É nesse sentido que explicações surgiram para justificar a guerra iniciada em 1936, aquela que afirma não ter sido uma guerra entre compatriotas, mas sim de uma luta pela "independência" numa tentativa de salvar Espanha contra invasores estrangeiros que, supostamente, pretendiam entrega-la à URSS (HYPÓLITO, 2013, p. 25).

Com a morte de Franco, em 1975, outros discursos surgiram, como o da reconciliação nacional, utilizado massivamente durante o período de La Transición Democrática, o qual consistia em uma espécie de acordo geral visando ao esquecimento de tudo o que o franquismo havia feito. Assim, o franquismo anistiava os antifranquistas de seus delitos contra o regime e os franquistas também se anistiavam de tudo o que haviam cometido (PRIETO, 2009, p. 131). Nesse período, a Guerra era vista como uma 
"locura colectiva"5 que jamais deveria se repetir na história da Espanha, devendo para tanto contribuir as forças políticas, sociais e econômicas (AGUILAR FERNÁNDEZ apud JELIN (1998, p. 46).

No entanto, a memória dos vencidos não foi facilmente apagada, já que a produção cultural entrou em cena de forma resistente contra o esquecimento, contrastando com as políticas da Memória e História oficiais. Trata-se de uma forma de denúncia por meio do teatro, do cinema, das narrativas, da poesia, objetivando a rememoração das vítimas do franquismo em contraste às políticas da Memória Oficial. Assim, Jelin (1998, p. 41) defende a presença de mais de uma memória, mais de uma visão e interpretação do passado, visto que a narrativa nacional é a dos vencedores, entretanto há outras em forma de relatos ou como práticas de resistência frente ao poder que apresentam narrativas diferentes com relação ao passado, ameaçando o consenso nacional que tanto se tenta impor. É nesse sentido que vemos boa parte da produção poética de García:

\section{$[\ldots]$ \\ Terra en suas dores eternizada \\ Terra con palabras nos vitrais \\ Terra que continúa escravizada. \\ Terra contida en inmensos ais \\ Terra interior sempre flaxelada \\ Terra venturosa en ecos invernais. 6}

(GARCÍA, 2007, p. 84)

Nestes versos, a imagem de uma Terra que vive uma dor eterna. Se é eterno, teve um começo, mas não teve um fim. Logo, compreende-se que não é possível apagar as narrativas dos vencidos, visto que tudo o que eles viveram ainda permanece na memória, eternizado. Essa ideia é reafirmada com o uso do verbo "continúa" e dos adjetivos "escravizada" e "flaxelada". Se há o outro lado da história a ser contado, esse é digno que se faça presente. Para isso, a memória insiste, obstinada, na sua presença, como vemos, ainda, no soneto 14, da obra Abrilsonetos:

\footnotetext{
${ }^{5}$ Tradução nossa: "loucura coletiva".

6 Tradução nossa: "Terra em suas dores eternizadas / Terra com palavras nos vitrais / Terra que continua escravizada. / Terra contida em imensos ais / Terra interior sempre flagelada / Terra venturosa em ecos invernais."
} 
Lémbrome, aínda, da miña escola

Do campo e da capela do San Ciprián

do mestre, inmerecedor de esmola,

que embrutecía aos nenos de Merlán.

Cantaba diante da pizarra ao sumar

e lembrábanos o Rei en seu Escorial

e aprendíanos asneiras para soñar

coa esquizofrenia do heroe nacional.

\section{$[\ldots] 7$}

(GARCÍA, 2007, p. 14)

Nos versos acima, o eu lírico lembra desagradavelmente dos tempos de escola, mais especificamente do mestre de Merlán, o qual não lhe permitiu participar de uma excursão devido à sua manifestação pública de que Deus não existia (TORRES, 2015, p. 20). Transmissor de uma educação totalmente tradicional, o professor, de forma autoritária, "embrutecía aos nenos de Merlán” não só com atitudes direcionadas de forma pessoal, mas também de forma coletiva: “[...] lembrábanos o Rei en seu Escorial / e aprendíanos asneiras para soñar / coa esquizofrenia do heroe nacional", ou seja, memória e história oficiais impostas.

Nessa perspectiva, as memórias de Xosé Lois García podem ser vistas como um signo de resistência contra o apagamento da história dos vencidos (BENJAMIN, 1986), na qual, o passado se destaca. Entretanto, seu destaque não está no nível da continuidade, mas na interrupção, na descontinuidade, segundo o que defende Jeanne Marie Gagnebin:

Benjamin tenta pensar uma "tradição" dos oprimidos que não repousaria sobre o nivelamento da continuidade, mas sobre os saltos, o surgimento (Ur-sprung), a interrupção e o descontinuo: "O continuum da história é dos opressores. Enquanto a representação do continuum iguala tudo ao nível do chão, a representação do descontínuo é o fundamento da autêntica tradição" (GAGNEBIN, 1999, p. 99)

\footnotetext{
7 Tradução nossa: "Lembro-me ainda da minha escola / Do campo e da capela San Ciprián / do mestre que não merecia esmola / que embrutecia as crianças de Merlán. / Cantava diante do quadro negro ao somar / e fazia-nos lembrar o Rei em seu Escorial / e aprendíamos asneiras para sonhar / com a esquizofrenia do herói nacional".
} 
Há, assim, o resgate da memória coletiva de um povo nas margens da história oficial. Como vimos, enquanto há uma história contada pelos vencedores, existe outra história, pois, apesar de serem considerados vencidos, o chão ficou marcado, visto que eles viveram experiências, repassaram-nas e fizeram a sua própria história. Nesse sentido, Benjamin questiona: "Pois não somos tocados por um sopro do ar que respirado antes? Não existem, nas vozes que escutamos, ecos de vozes que emudeceram? Não têm as mulheres que cortejamos irmãs que elas não chegaram a conhecer?" (BENJAMIN, 1987, p. 223).

Esclarece-se, pois, o fato de que mesmo os vencedores tendo a sua versão da história, não significa que não existam outros que façam uma nova história, o que não é tarefa fácil, dadas as profundas raízes da história daqueles que trinfaram.

Para Benjamin, os historiadores contribuem para que a história oficial não seja extirpada, pois o acesso aos fatos históricos contados por eles só distorceu o que realmente aconteceu. Isso se deve ao fato de alguns historiadores manterem uma posição neutra para a reprodução dos fatos de forma objetiva, sem posicionar-se criticamente, sem deixar espaço para interpretações. Benjamim rejeita este posicionamento e não aceita a versão dos vencedores, dos supostos heróis da nação. Ele defende ser possível, sim, recuperar as memórias presas pelas narrativas triunfantes.

\section{Considerações finais}

A partir do exposto, vemos o quão importante são as ações da produção cultural que por meio do teatro, das narrativas, da poesia, trazem às claras as memórias dos que foram perseguidos e calados, desempenhando a "tarefa de escovar a história a contrapelo" (BENJAMIN, 1987, p. 225).

A poética de Xosé Lois García é extensa; ainda em produção, o autor já publicou mais de 70 livros. Mas mesmo no pequeno recorte apresentado neste artigo pode-se observar que, a partir de experiências, sentimentos e lembranças próprias, por meio da voz do eu-lírico, houve a expressão de fatos de um período histórico que marcou o povo galego. Daí a compreensão de que memória e história confluem, visto que a primeira pode se atrelar à segunda e ser de grande valia para a produção de discursos, no caso do presente trabalho, discursos pelo viés dos vencidos, daqueles que vivenciaram as barbáries da guerra e sobreviveram para contar, tendo em vista que "Esa ferida aínda 
supura guerra, / cheira e fere en terra allea; / a terra fácil e incompleta" ${ }^{\text {. }}$ (GARCÍA, 2005, p. 103)

\section{REFERÊNCIAS}

BARROS, José D’Assunção. Memória e História: uma discussão conceitual. Revista Tempos Históricos, n. ${ }^{\circ}$ 15, 2011.

BENJAMIN, Walter. Magia e técnica, Arte e Política: Ensaios sobre Literatura e história da cultura. São Paulo: Brasiliense, 1987.

GAGNEBIN, Jeanne Marie. História e narração em Walter Benjamin. 2. ed. São Paulo: Perspectiva, 1999.

GARCÍA, Xosé Lois. Merlán. In: Tempo precario. A Coruña: Ediciós do Castro, 1988. Kalendas. Vigo: Xerais Galicia, 2005. Abrilsonetos. In: No imo do tempo. A Coruña: Touxosoutos, 2007

HALBWACHS, Maurice. A memória coletiva. São Paulo: Centauro, 2004. Los marcos sociales de la memoria. Barcelona: Antropos, 2004.

HYPÓLITO, Bruno Kloss. O cinema e a querela De Memórias do Franquismo na Espanha Contemporânea: os casos de Silencio Roto e El Laberinto Del Fauno. 2013. 197f. Dissertação (Mestrado em História) - Faculdade de Filosofia e Ciências Humanas, Pontifícia Universidade Católica do Rio Grande do Sul, Porto Alegre, 2013.

JELIN, Elizabeth. Los trabajos de la memoria. Madrid: Siglo XXI de Editores S.A, 2002.

LOWENTHAL, David. Como conhecemos o passado". In: Projeto História: revista do Programa de Estudos Pós-Graduados em História, PUC, São Paulo, n. 17, 1998, p. 63201.

MALUF, Marina. A reconstrução do passado. In: Ruídos da Memória. São Paulo: Siciliano,

NORA, Pierre. Entre memória e história: a problemática dos lugares Tradução Yara Aun Khoury. Revista do Programa de Estudos Pós-Graduados e História e do Departamento de História da PUC-SP, São Paulo, n. ${ }^{\circ} 10,1993$, p. 7-28.

\footnotetext{
${ }^{8}$ Tradução nossa: "Essa ferida ainda supura guerra / cheira e fere em terra alheia".
} 
PRIETO, Lourenzo Fernández. Actitudes sociales y políticas en la denominada recuperación de la memoria histórica Galicia: El proyecto de Investigación Interuniversitario 'Nomes e Voces'. Pasado y Memoria: Revista de Historia Contemporanea, Galicia, n. ${ }^{\circ}$ 8, 2009, p. 131-157.

TORRES, Camilo Gómez. De rebeldias, soños e irmandades. Noticia de Xosé Lois García. Xermolo, 2015. 